\title{
Experience of Palestinian Children Facing Consistent Intermittent Traumatic Events: A Descriptive Phenomenological Exploration
}

\author{
Farid Abu Liel Rn, Mmhn, Denise Ziya Berte, ${ }^{2, *}$, Sabrina Russo $^{2}$ \\ ${ }^{1}$ Department of Public Health, An Najah National University of Palestine, Palestine \\ ${ }^{2}$ An Najah Child Institute, An Najah National University of Palestine, Palestine
}

Copyright $\odot 2017$ by authors, all rights reserved. Authors agree that this article remains permanently open access under the terms of the Creative Commons Attribution License 4.0 International License

\begin{abstract}
Introduction: The objective of this research is to provide a qualitative analysis of the effects of living in a zone of militarized activity under hostile occupation on minor aged children. Ongoing political conflict affects the individual, cultural, societal and economic lives of children creating significant challenges for positive development in the area of mental health in particular. There is a grave lack of knowledge related to the way children understand the geo-political realities in which they reside. This study works to provide a descriptive analysis from the individual perspective, of the experience of Palestinian children in an area of high frequency violent conflict under a situation of hostile resisted occupation with the goal of deepening the awareness to the process of adaptation to traumatic stress and of understanding the immediate and long term effects of traumatic exposure while highlighting areas for support and positive intervention. Methodology: The investigation incorporated a qualitative phenomenological descriptive design utilizing guided interviews. 15 children were selected in a purposeful representational sample. Children were identified due to their personal participation in civil protests, and/or having direct experiences as victims of occupying military action (including having tear gas canisters thrown at them, being shot with rubber bullets and live ammunition, being arrested, being assaulted by soldiers, being interrogated, having their homes entered and inspected without permission, having their parents beaten and arrested in their presence, etc.). Data was analyzed by using Giorgi's phenomenological psychology method (1985). Results: Three major themes and ten sub-themes were identified: (1) Exposure to Traumatic Events (threats to well-being, witnessing violence, direct violence, deprivation of freedom, lack of safety and fear); (2) Normalization (trauma play, underestimation of risk); (3) Resilience (the active creation or search for positive support in the current environment, self-efficacy, awareness of self, feelings of belonging, and belief in trusted adults). Conclusion: The findings demonstrate the importance of understanding the
\end{abstract}

experience of continual intermittent traumatic events on the psychological, behavioral, and cognitive development of children living in militarized conflict zones and the important role that efficacy, community support and trust play in supporting resilience in such circumstances.

Keywords Trauma, Phenomenology, Children, Resilience, Palestine

\section{Introduction}

Children and youth residing in militarized conflict zones in various geopolitical areas of the world are exposed on a regular, sometimes daily basis, to violence that is institutionalized and pervasive in their environment. For these children and youth, exposure to traumatic events can result in cognitive, behavioral and emotional challenges [1]. If not addressed, childhood experiences of trauma can manifest themselves later as clinical disorders including depression and PTSD (post-traumatic stress disorder) as well as maladaptive behavior patterns such as those found in addiction, serial unemployment, and an inability to form lasting intimate relationships. Adolescents and adults often demonstrate higher levels of immediate symptoms then younger children, such as depression, fear, nightmares, restlessness, psychosomatic illnesses, aggression, and feelings of helplessness, but children exposed to traumatic events, despite fewer reported symptoms initially, demonstrate long term vulnerabilities in the areas of adaptation and eventual mental health diagnosis [2].

In areas of political armed conflict, younger children are affected not only by the conflict itself, but by their social environments, including the reaction of parents, adult caregivers, and community institutions to the situation. Intervention programs may target schools and other child-based service providers, recognizing their roles as 
community actors in tandem with identifying individual children in order to create holistic stable safe environments for rehabilitation [3].

Palestinian children in specific areas or in targeted groups have experienced intense traumatizing events, on a consistent basis that continues into the present. These young people are exposed to loss of personal freedom and movement, physical assault with related injuries, humiliation, detention or arrest, tear gas inhalation, home demolitions, and death of peers, family members, and community leaders [4].

A child's reaction to a trauma or a life-threatening event can vary depending on a number of factors, including age, prior experience with trauma, and available support systems. While responses may include anxiety, fear, and loss of self-efficacy (classic symptoms of Post-Traumatic Stress Disorder), in children and youth the consequences of exposure to trauma do not always follow a clear diagnostic path. While some children withdraw and deny the event, others become hostile and aggressive. All of these responses seemingly serve the purpose of psychologically protecting the emotional well-being of the child, some more effectively than others. For example, if a child isolates him/herself from family, school and community, they may reduce individual stress but also receive less benefits of a social community or family based buffer. Sadly, Palestine, with its current situation of hostile occupation and scattered militarization, is fertile ground for the psychological trauma of children, predicting both immediate and long-term effects [4].

For some Palestinian children exposure to sudden and unexpected events cause damage to their perceptions of safety and psychological stability as well as disrupt the very social structures which they need to support them (including families, schools, religious/recreational activities, etc.) making rehabilitation even more challenging [3\&5]. In addition, children who live under circumstances of violence and armed conflict are often forced by their reality to take on adult responsibilities and concerns much earlier than developmentally appropriate, losing the innocence and carefree play of childhood, and adding to their vulnerability [6-8].

In a survey conducted by Espié et al (2009) in Gaza and the West Bank, $25.8 \%$ of child participants met the internationally standardized criterion of Post-Traumatic Stress Disorder (PTSD). Witnessing a murder or torture, being threatened, and experiencing the destruction of their property were found to be the main contributing factors to the existence of PTSD in the child respondents [9]. A Palestinian study in 1999, found that there were high incidents of post-traumatic stress responses in primary school children who had experienced some act of conflict or war. $73 \%$ of child respondents had PTSD reactions of at least mild severity, while $39 \%$ of children surveyed reported moderate to severe reactions [10]. The children that were most likely to exhibit PTSD reactions were those from living in refugee camps dealing with the secondary consequences of the initial traumatic events [5]. It was found that the Palestinian internal refugee population experience mediating adversities (relocation, school disruption, etc.) to a greater extent than those living in their ancestral areas leading to higher levels of symptomology related to trauma [5].

The Vermont CUPS Handbook (2005) defines trauma in children as "a physical or psychological threat or assault to a child's physical integrity, sense of self, safety or survival, or to the physical safety of another person significant to the child" [11]. Psychological trauma may occur acutely, as the result of a lone traumatic event, or chronically, resulting from multiple, repeated exposures to extreme stress [12].

Acute stress disorder (ASD) is a psychological state in which the symptoms of trauma remain after the event has ended, continuing to affect the child and his or her ability to function up to six months after the event. If overwhelming stress continues and the child's neurophysiologic responses remain aroused for more than 6 months, then the term Post-Traumatic Stress Disorder (PTSD) is used to describe the child's symptom profile according to the DSM5, 2013 [13].

Children living in militarized areas such as targeted areas of Palestine with consistent exposure to physical threat and violence to self or significant others are at greater risk for exhibiting negative effects in physical symptoms such as nocturnal enuresis, panic, somatic disturbances, and hyperactivity [4]. The first signs of psychological trauma observed in a sample of children residing in Palestine, after the outbreak of the second intifada (a period of popular uprising which was met by occupation troops with severe acts of violence against the civil population and community restriction including curfews, checkpoints, house invasions, etc.) were nightmares, sleep disturbances, bedwetting, speech difficulties, poor concentration, regressive behavior and thoughts of death, according to parent interview [4].

Despite the difficult circumstances of their lives, children in areas of high militarized conflict, including Palestine continue to demonstrate startling strength and resiliency. Resilience is a term that describes an individual's ability to confront extreme external challenges and life conditions, while continuing to move forward with personal goals. Resilient people are able to utilize their skills and strengths to manage their emotions and recover with positive motivation from negative life events. Many factors may contribute to resilience in the lives of children facing hardship including such a supportive inclusive community, which may increase feelings of self-efficacy, which is intricately related to resilience [4].

\section{Aims of the Study}

The aim of this study is to investigate and describe the experience of a group of Palestinian children in an area of 
high geopolitical conflict facing at least weekly and at times daily traumatic events over a period of ten years. Military occupation poses a challenge to the mental health of children in Palestine, and it is influenced by a set of complex and interactive individual, social, cultural, and economic factors. A lack of research in this area makes it difficult to understand the phenomena in relation to the unique cultural and social context of Palestine. Understanding these factors is critical to the provision of effective and culturally appropriate care. A qualitative approach was utilized in order to document narratives of the children themselves, with the goal of an increased first hand documentation of this important issue.

There is a lack of knowledge regarding the manifestations of trauma among children living in protracted militarized situations (including ongoing exposure to violence and threat): the current research strives to examine and understand such experiences from the perspective of the children affected including both coping with specific violence related stressful events and the context of daily living in an overwhelming environment, as well as recognizing the characteristics related to the construct of resilience in its complex and variable meanings in the lives of these children.

Findings help to address the experiences and needs of children in protracted conflict zones in Palestine and across the world.

\section{Research Questions}

1) What is the experience of children living in a targeted Palestinian village under occupation (including incidents of violence as well as normal developmental functioning)?

2) What are the feelings and thoughts that accompany the daily life events of these children (traumatic and otherwise)?

3) What are the underlying psychological risks for children and youth living in protracted traumatic environments?

4) How does continual exposure to violence affect cognitive, emotional and social development of children in the situations of consistent geopolitical military threat?

5) To what extent do these children demonstrate need of psychological support services vs. naturally occurring factors promoting resilience?

This study explored the phenomenological experience of children exposed to frequent and intense militarized violence and threats to well-being. As such, the findings will enhance the understanding of the effect of trauma on children who live in geopolitically violent environments to understand the impact of such traumatic events on their daily life, and to explore their feelings and thoughts. Such information is crucial in order to plan and assist the children and their caretakers to address cognitive, emotional and social consequences of these experiences. The results of this research will enhance the professional gap in knowledge and add data related to the phenomena of children living under protracted conflict zones with resulting traumatic experiences.

\section{Methodology}

This study used a qualitative research approach, producing a description of an individual's lived experience of a particular phenomenon in their own words. The goal of this type of research is to provide a subject driven analysis of the events and the subsequent internal consequences (cognitions, emotions, etc.).

This investigation focused on the experience of threat and violence (individual and familial), community response, and protective factors in the life of each participant. All participants were children living in a high conflict zone in the West Bank of Palestine.

Descriptive Phenomenological Analysis, according to Smith, J.A. \& Osborn [14], is a methodological approach that seeks to understand how individuals experience and attribute meaning to the events of their lives. It also recognizes the active role of the researcher in the investigation process, specifically the subjectivity and personal biases that they will invariably bring to the study [14].

The fundamental principle of the phenomenological approach is that the researcher must remain true to the subjective perceptions of the participant and how they reveal themselves [15]. To achieve this critical goal, Giorgi, (1975) created a phenomenological method to aid the analysis of individual interview data. The aim of phenomenological psychology is to produce "accurate descriptions of human experience." Phenomenologists working using this method create descriptions provided by others, gathered through interviews [16].

In attempting to obtain unique and individualized descriptions, a researcher must set aside any prior thoughts or judgment about the phenomenon under study. In so doing, the researcher "brackets" the phenomenon. The "bracketing" allows the documented description to reveal the personal reality of the individual for whom the phenomenon under study appears [17] . What needs to be avoided by the investigator are those presuppositions, claims made from objective science or other authoritative sources, that may limit the report of the participant [16].

Phenomenology attempts to offer insightful descriptions of the way the world is experienced by affected individuals, without external interpretation [18]. In this context, the children themselves facing violence on a continual intermittent basis are at the center of the inquiry. To avoid bias in the interpretation of results, the period of study was elongated to minimize distortion and all subjects were 
asked to later verify if the observations concerning them were correct and reflective of their experiences.

\section{Participants}

The participant sample included 15 children between six and 14 years of age from a village close to a zone of high conflict in the West Bank of Palestine. The mean age was nine years. There were eight males and seven females included. The children were identified due to their personal participation in protests and/or experiences of direct victimization of military action including but limited to: having tear gas canisters thrown at them, being shot but rubber bullets or live ammunition, being physically assaulted by occupation military personnel, having their homes entered without permission, being arrested, having immediate family members arrested, etc. There are over 18 villages in Palestine that have taken a stance of resistance to the occupation and who have staged protests on a weekly basis for over ten years, of which the village studied is included. The particular village is located very close to an illegal settlement and has continual conflict over territorial boundaries. In response to their active resistance, families and individuals in the village are exposed to frequent military incursions including night raids, arrests, etc., as well as weekly attacks related to the public protests including tear gas, the spraying of "skink water" a chemically toxic liquid causing burning to the skin and a repugnant odor, shooting with rubber bullets, face to face alterations and assaults by occupation forces and open live ammunition. There have been at least two deaths in the community of adult leaders related to political activities.

Purposeful sampling was used for the recruitment of participants for this study. Purposeful sampling is commonly used in qualitative research. It involves selecting research participants according to the needs of the phenomenon of study [19]. Researchers choose participants who have experiences that could provide a richness of information that is suitable for detailed research in the area of study in this case direct exposure to violence and threat of well-being for themselves or close family members [20]. Children with developmental disorders or whose family consent could not be obtained were excluded.

Potential participants and their families were informed about the study and asked for interest. Both child and parents had to agree voluntarily and no incentives were offered. Participants were reminded on all occasions of their right to terminate the interviews at any time per their request. All of the children had histories of public speaking related to their experiences and appeared comfortable in the role of story-teller. No child expressed distress or discomfort during the interviews. The children had met the interviewer previously and were visibly familiar with him. All participants denied the right to have an adult caretaker with them during the interview, although all were in the immediate vicinity of their families.

All interviews were held in Arabic and recorded thus. Translation into English occurred during the second draft of the narratives, after they were clearly established in Arabic by the primary interviewer.

\section{Instruments and Measures}

A semi-structured interview guide was created that was specific to the experience of the sample group. The interview guide acted only as a support to ensure that important issues were not forgotten and to organize the discussion by designating the order in which different themes were addressed. The interviews were designed to mimic conversation relaxed and natural, rather than formal. The interview guide (Appendix A) was tested in a pilot case and evaluated by a committee of experts in the field and familiar with the sample.

\section{Procedures}

The interviews were held in a private room in the selected participant's home. Caretakers were available but not present. No participant asked for the presence of the caretaker during the interview, although they were informed this was possible. A consent form from the parents was obtained as well as verbal agreement by the child, and an information form about the aim of the research and the rights of the participants was delivered. Basic demographic information was provided by parents. Follow-up psychological services were available but unsolicited.

Each interview took between 45 and 60 minutes. Interview questions were open-ended allowing for free-expression of the child. Follow-up questions sought concrete descriptions of events, feelings, etc. [21] (See Appendix A). Questions addressed the children's experience of violence and threat, their own reactions and those observed in their family and community as well as the children's strategies for creating a feeling of safety.

Interviews were recorded and transcribed verbatim. They were then analyzed by meaning and merged in a systematic format to produce thematic representations of the findings. They were then translated into English. Some quotes were saved in their original form to insure expressive validity.

\section{Data Analysis}

Analysis was performed within the stages of phenomenological reduction as outlined by Robinson \& Englander and Giorgi, which includes reading the entire description for holistic content, identifying meaning units within a psychological perspective, transforming individual expressions into psychological language, and finally synthesizing transformed meaning units into a consistent 
statement of the structure of the phenomenon across subjects [16] [21].

\section{Reliability and Validity}

Potential interviewer bias was addressed on various levels. Prior to the interviews, the interviewer identified expected findings and explored feelings and background related to the subject matter with an external supervisor in order to recognize potential issues of transference [22]. All interviews were recorded and transcribed verbatim, raising the level of credibility [22].

The children and families were given no incentive to participate, therefor reducing concerns about falsified accounts. Parents were not present during interviews nor were they given individual feedback about the responses of their child in order to encourage children to feel comfortable to speak openly about their individual experiences. No child requested the presence of their parents nor did they express or exhibit signs of distress during the interview process or after. Psychological services were made available but were unsolicited after the study period.

\section{Evaluating the Quality of Phenomenological Research}

In phenomenological research, "value is established by honoring concrete individual instances and demonstrating fidelity to the phenomenon" [23]. Often, readers are invited to judge the soundness of the analysis of the data by including respondent's exact words and other raw data into the presentation of findings.

"The quality of any phenomenological study can be judged in its relative power to draw the reader into the researcher's discoveries allowing the reader to see the worlds of others in new and deeper ways" [24].

\section{Ethical Considerations}

This study was approved by An-Najah National University's Internal Research Review Board. Consent was obtained from informant's families to take part in the study and verbal agreement solicited from the child participants. These considerations are based on the Helsinki Agreement of the World Medical Association [25] on ethical guidelines for nursing research on volunteerism, to withdraw from the project, potential risks or discomfort, anonymity, confidentiality and contacts for any information needed.

Children were continually monitored for signs of distress during the interviews. On the contrary the participants were enthusiastic story-tellers and sometimes asked for extended time to talk. No participant requested a caretaker with them during the interviews, despite being clearly offered. As participating in interviews is a regular activity in their environment, the children accepted the conditions of the study without question or concern.

Confidentiality of the records was insured at every possible level, using coded numerical systems in lieu of names. Files were kept in locked vesicles and destroyed after analysis. Information about the village is kept confidential in all publications per IRB recommendations.

Psychological support services were available for any child or family who requested them related to the inquest of the study. Follow up calls were made to parents periodically after the study to insure no mal-affect to the children and no concerns were noted.

\section{Results}

From the analysis of the interviews, three major themes and ten subthemes were identified:

\subsection{Theme One: Exposure to Traumatic Events:}

Exposure to Traumatic Events was the major theme emerging from the experiences of the children. All of the respondents related having been exposed to a variety of traumatic events. Subthemes included life threatening events, being victims of direct violence, witnessing violence, deprivation of freedom, and lack of safety.

Respondents expressed their experiences as follows:

\subsubsection{Life Threatening Events:}

A life threatening event is a situation in which a person has the fear of death or serious physical injury to self or significant others. The children of our sample all related situations in which they perceived themselves or others could die.

A 9year-old respondent reported the following:

"I remember that we went to my grandpa's house; the army started to fire tear gas and we went away from the windows; some of the curtains burned and the gas bottle in the stairs exploded; we couldn't escape so they took us down from the windows.” $R 3$

Another stated:

"We started to run away from the gas so we didn't suffocate, and they tried to arrest us and wound us". R1

In response to a very close range explosion of tear gas:

"I was scared because it hurts my eyes; I couldn't see, and if I ran, maybe I would fall down and something bad would happen". R2

\subsubsection{Witnessing Violence:}

The entire sample of respondents in this study reported to have witnessed violence against friends and family members

"When the army entered the village and started to search the house, sometimes they would take my dad and my brother, and I would be afraid. Once they took my father 
on Friday and they left him at night; they tied him up and hit him on his feet; he was without shoes". R10

Many episodes of lesser aggression were reported by the children as triggers for a fear or anticipation of a more serious event.

"Sometimes we would all be sitting around together and the kids and I would hide from the soldiers while the young men would be in the front throwing stones, and we would feel like something bad was going to happen. Once my cousin got injured in his finger and it had to be amputated." R4

\subsubsection{Direct Violence:}

The majority of children in the study related being direct victims of violence themselves.

"The first time I went to the demonstrations I was in the $4^{\text {th }}$ grade. I started to chant and I was afraid. We started chanting in demonstration and the soldiers told us we have 5 minutes to finish the demonstration. When we arrived to the house closest to the army, the five minutes had finished and they started to beat us." R2

Another child reported the following:

"The army started to enter the village from all places; they surrounded the village, and when we sent to the demonstration and reached the army, they started to fire. This Friday they arrested three female demonstrators; they threw tear gas at us at close range, and they shot one of us with tutu bullets" R8.

('Tutu' bullets are 0.22 caliber bullets that were outlawed by Israeli courts in 2001 as crowd dispersal methods but are still reported as used during protests)

Another of the respondents said:

"We faced them and they started to throw tear gas, and shoot rubber bullets and so on. A lot of youth and children were present, but the soldiers didn't care what the age of the children was, or whether there were women, elderly or solidarity foreigners there. They don't care about anything, and they continued to throw tear gas until we started to suffocate, and then they tried to target us with rubber bullets." R1

\subsubsection{Lack of Safety:}

Safety is a basic need for survival, as important as food and shelter; a lack of the perception of being protected for a child may result in serious impairment of his growth and psychological development. Children's responses related to safety were prevalent.

"They enter the village at night and raid the houses usually; they throw tear gas and noisy sounds bombs, and sometimes they use the jeep speaker to be loud and make people afraid; they irritate me and I am afraid".R17

"When they throw tear gas I close my eyes, and then I go home and close windows because the army fires on the houses, then I hide in the sleeping room, and if they come to the house they search everywhere. Once, while I was sleeping, the army came with the dogs I was scared when heard the dog, and I said I must go to sleep because I am afraid".R11

"Sometimes they enter the houses; they raid our house and they ask if we know anyone who threw rocks at them. We tell them that we don't know. Once I was woken up in my room and confused; suddenly I left the room I was surprised that they were in our home. I was scared". R14

Another issue was lack of safety even when away from the home village.

"I go with general transportation from here to Ramallah. Sometimes there is a checkpoint with soldiers that has closed the road so we can't go to school, so we miss our lessons". R1

\subsubsection{Fear:}

Ethnologists define fear as "a motivational state aroused by specific stimuli that give rise to defensive behavior or escape" [26]

Children sampled were ambivalent about admitting their fears, possibly due to the positive identification with bravery and courage prevalent in their village culture.

"Last Friday the army fired a kind of gas that I don't know that was an orange color. I became a little afraid, and then I went back to avoid suffocation". $R 9$

"Yeah, the army enters a lot of times, but more in the night; the day before yesterday they entered and I kept sleeping; when the army started to shoot I kept sleeping, even though my brothers went out, I kept sleeping because I was afraid". R10

\subsection{Theme Two: Normalization:}

Normalization refers to the process through which ideas and actions come to be seen as 'normal' and become taken-for-granted in everyday life due to frequency of occurrence.

It is proposed that children exposed to high levels of violence evidence "cognitions that normalize violence and mitigate effects of exposure while increasing risk for violent behavior, thus perpetuating further violence in the very process of adapting to it psychologically" [27].

However it has also possible that normalizing has a protective factor in minimizing negative experiences where exposure to violence is continuous and unavoidable.

Respondents expressed this theme as follow:

"the problem is that when I speak my eyes look like I laughing, sometimes I went to the mountain or to the valley, we gathered in the village and go down near the gas station, start to sing, sometimes when arrived down we closed the area to prevent them to enter the village if they tried to...they stopped. Sometimes we do joke on them."R4

Another respondent said that after violent protests:

"We go home sit with the family, we have our lunch and take a rest”.R6

For the children of our sample, all of whom were born during the current violence, there is no other "normal" 
therefor inquiring about a non-conflict time was not possible.

\subsubsection{Role Playing the Traumatic Events:}

Play serves crucial functions for children. It enables children to practice new and more advance behaviours. It teaches them to anticipate the future. At the same, time play allows for the discharge of a child's emotions. Under extreme stress, children may use play to try to master fears and anticipate the future.

This theme was expressed as following:

"There was the (play) army and the kids built the tower, and we were the Arabs, and started to throw rocks. If any one of us was injured by small stones, the army took him, the army would start to fire, then we would escape to hide in some place not in the neighborhood; yeah, we escaped". R3

Another respondent explained:

"Sometimes when we play Arab and army in the presence of the youth who demonstrate, the real army would come and we would have to stop the game". R4

\subsubsection{Underestimation of Danger:}

The perception of danger differs from person to person and must be analyzed in the frame of its cultural and actual environment. For children facing daily threats, it may be difficult for them to distinguish or avoid high risk situations or activities

A respondent said:

"We were here in the back because we made plans for how we will reach the house, and when the army was not alert to us we moved around my grandpa's house and they were near the gas station. I tried to break down the barrier of fear. They come from countries I don't know, like Britain, and they claim that it's their homeland." $R 2$

\subsection{Theme Three: Resilience:}

Resilience is the ability to remain psychologically healthy and achieve personal successful despite negative life circumstances. This theme is expressed as follows:

"We hope that our hard work will not be in vain. We will try to liberate Palestine until the last day of our life, and Palestine will have its freedom and there will be no existence for Israel, and we will have peace with safety". $\boldsymbol{R} 1$

What emerged from the narratives is that resilience was supported appeared by facing trauma actively and rather than avoiding it. Similarly, the children who had participated in peaceful resistance had a sense of power and control, that seemed to reduce feelings of victimization.

\subsubsection{Self-efficacy:}

Self-efficacy is the belief that you are capable to predict and affect the outcomes of life; this sub-theme expressed as follows:
"I start to move from one window to the other to see them (the army that enters the village) around the house". RI

“When someone is martyred, it is my nature that I don't let anything get to me; most of the time I smile even there is something bad, like when they arrested mom or someone else, I even started to play with my little brother and make him smile". R5

"When we met, we made a beautiful plan to retrieve the land that the army took". R10

Finding solutions during an emergency situation, it is also considered a sign of self-efficacy:

"Gas...it looks like the army added something to it because it caused more tearing. So I couldn't run. I brought a scarf with me, and I put it around my face and despite this, there was still a reaction to the gas". $R 2$

\subsubsection{Awareness and Belonging:}

The feeling of belonging, describes the human need to be an accepted member of a group. Belonging implies a relationship that is greater than simple acquaintance or familiarity; it is based on loyalty and a shared destiny.

For the children interviewed the identification of belonging to their land, community and family resulted as a protective factor.

"I would like to be a tourist guide...so when people come here from outside I can introduce to them the history of Palestine and my village". R6

"I would like to be a lawyer, if I defend a Palestinian I can get him out of prison and also the other prisoners..." $\boldsymbol{R} 2$

There appears to be a relationship between belonging and meaning which may explain its importance as a protective factor [31].

Children in the sample expressed a well-defined understanding of the geopolitical situation of their community and could demonstrate knowledge about their individual and geographical rights:

"It means freedom for my country and feeling safe in it, with peace and justice with no occupation; a country like all countries with no occupation, where children can live like all the children in the world" $R 1$.

The events that occur in the village are discussed and explained to the children, which appears to increase their awareness and active participation in communal life as well as enhancing their capacity to predict and manage their environment.

One of the respondent, 9 years old, explained the strategic plan of the soldiers during night raids:

"There were many young men and the soldiers raided our house and they searched and destroyed everything; they arrested youth and tortured them; they took a picture so they could make a map for the whole village with the pictures of members of each house and numbers for all the houses. For example, this house is No. 5 and belongs to this youth and this one, and so on, so that they know where to go whenever they come to arrest this youth".RI 


\subsubsection{Trust in Adults:}

The importance of a child's close relationship with a caregiver cannot be overestimated. Through relationships with important attachment figures, children learn to trust others, regulate their emotions, and interact with the world; they develop a sense of the world as safe or unsafe, and come to understand their own value as individuals.

Our ability to develop healthy, supportive relationships with friends and significant others depends on our having first developed those kinds of relationships within our families.

In the current study the entire sample of respondents reported they were reassured by the presence of their parents, when responding to the question: "Where and with whom do you feel safe?" The children did not identify safe "places" but safe "people"

This is expressed as follows:

"During the demonstrations we went to the nearest house, or I would go with adults like my uncle or my father; I would go with anyone knows what to do."R6

"To be with Daddy near the soldiers where he took a photo".R3

\section{Conclusions}

"Safety means freedom for my country and feeling safe in it, with peace and justice with no occupation; a country like all countries with no occupation, where children can live like all the children in the world" R1.

During this study the experience of Palestinian children facing consistent ongoing violent events and how they understand, respond, and protect themselves from the resulting stress was investigated. Three major themes, Exposure to Traumatic Events, Normalization and Resilience along with ten subthemes emerged from our analysis of the in-depth interview with the children. No significant differences related to age and gender were identified.

Children are the best sources of information about themselves. The current sample was intentional and included respondents from different backgrounds and ages all having personal experiences of threat and victimization to reflect representation of the full range of experience in this village.

The raw descriptions of the exposure and understanding of minor children to acts of brutal violence and ongoing trauma, documented in this investigation is startling in its simplicity and detail. All of the children interviewed had in common multiple occurrences of violence and trauma in their lives and the lives of their families. While the world is aware of these events, hearing the experiences in the words of the children is sobering.

The level of normalization and resilience, in the face of sometimes daily exposure to violent conflict and the protective role of both community action and the children's exposure to information and analysis about the situation including its history, cause and meaning offer a different and possibly innovative view of the situation of children in areas of high conflict. The idea that children can or should be active participants in political discourse and resistance and that such activities may have protective value offers a unique perspective deserving of further investigation.

Follow-up interviews with parents of the participants revealed that initially caretakers attempted to shelter children from observing protests and being aware of the political struggles of the community. During this time, caretakers report that children were exhibiting high levels of symptomology including nightmares, bed wetting and hyper arousal, etc. According to the caretakers, when the children were oriented through community awareness events and accepted as significant change agents, included in discussions and decision making, the parents perceive, and data upholds, behavioral symptoms decreased and eventually disappeared.

The results of the current study demonstrate the complexity for children and youth of coping within environments with frequent exposure to violence. Children are forced to integrate and normalize traumatic events to insure normal development, however, such integration itself may lead to a longer term inability to realistically evaluate risk or self-protect. In the included sample facing inevitable danger not as victims but as active participants, along with trusted adults, allowed children to develop a sense of self efficacy and strengthened feelings of belonging to their community. These factors may be the roots of the resilience observed.

The limitations of the information gathered in such a unique environment is obvious. The children interviewed in this investigations are not only victims of continuous intermittent violence, but also educated, informed active participants in a well organized resistance movement supported by trusted caretakers and as such may not represent the experiences of children in other circumstances. Their documented experiences however do offer a perspective on childhood activism and community organization that may be productive to consider.

\section{Discussion}

The first and primary recommendation in any study related to vulnerable populations in high conflict zones is and must be that individuals globally take steps to reduce the exposure of children to violent military conflict and whenever possible offer them protection and their inherent human rights to live in peace safety and dignity.

That being said this study demonstrates that for children who are caught in a situation of inevitable conflict, empowerment in the form of increased knowledge, active participation and inclusion in the community, can in fact be protective factors, despite the fact that such activities may 
increase actual exposure to traumatic events. Parenting and relationships with trusted adults was found to be a source of great importance in fostering resilience in this population, including strategies that increase communication with children to express their knowledge, understanding and feelings about current events and strengthening relationships with adult caretakers in the community. Supporting and educating parents in these areas is essential.

It is with gratitude and respect that we present the reports of these unique and insightful participants, in hopes that their contribution is equal to their efforts.

\section{REFERENCES}

[1] L. Dimitry. Imperial. (2012). A systematic review on the mental health of children and adolescents in areas of armed conflict in the Middle East. V38. I 2, pages 153-161, ac.uk.

[2] Burke,S.(2006). Children and War: Cycles of Violence. In Psych [Internet].

[3] Thabet, vostanis,P.(2000). Effect of trauma on the mental health of Palestinian children and mothers in the Gaza Strip. East. Mediterr. Health J.7(3):413-21

[4] Russo, S.(2014). Trauma and resilience. http://www.sci-italia.it.

[5] Qouta, S., El-Sarraj.( 2004). Prevalence of PTSD among Palestinian children in Gaza strip. Arabpsynet journal.

[6] Widom. (1999); Yule. (2001). The Effects of Chronic War Trauma among Palestinian Children. M.Altawil@herts.ac.uk. Chapter 7 p151-156.

[7] Yule, W.(2001). Post-traumatic stress disorder in the general population and in children. Journal of Clinical Psychiatry, 62, 23-28.

[8] Boothby et al. (1992). Handbook of Pain Assessment, Third Edition.p 82.

[9] Espié E., Gaboulaud V, et al.(2009). Trauma-related psychological disorders among Palestinian children and adults in Gaza and West Bank. International Journal of Mental Health Systems,3:21.

[10] Mousa Thabet ,A., Vostanis P.(1999), The effect of trauma on Palestinian children and mothers mental health in the Gaza Strip. www.researchgate.net

[11] Vermont CUPS Handbook.( 2005). Finding help for young children with social-emotional-behavioral challenges and their families. Federal Center for Mental Health Services to the Vermont State Department of Health, Division of Mental Health.
[12] Terr.(1992). Too Scared To Cry: Psychic Trauma in Childhood. Paperback Paperback - January 1, 1000

[13] Diagnostic and Statistical Mannual of Mental Disorders-V-TR. (2013). American PsychiatricAssociation [APA].

[14] Smith, J. A, Osborn, M.(2003). Interpretative phenomenological analysis. In J.A. Smith (Ed.), Qualitative Psychology: A Practical Guide to Methods. London: Sage.

[15] Husserl, E. (1960). An Introduction to Phenomenology. Dordrecht, The Netherlands: Martinus Nijhoff.

[16] Giorgi, A. (1985). Sketch of a psychological phenomenological method. duquesne unevercity press.

[17] Ashworth, P. D.(2006). Seeing oneself as a career in the activity of caring: attending to the life world of a person with Alzheimer's disease. International Journal of Qualitative Studies on Health and Well-being, 1, 212-225.

[18] Van Manen, M. (1990). Researching lived experience human science for an action sensitive pedagogy. new york : state univercity of new york press.

[19] Glaser, B., Strauss,A. (1967). Ths dicovery of grounded theory: strategies of qualitative research. New York : aldine De Gruvter.

[20] Patton, M.(1980). Qualitative evaluation methods. Beverly Hills ,CA:sage.

[21] Robinson, P., Englander, M.(2007). Den descriptive fenomenologiska humanvetenskapliga metoden. Vard I Norden, 83, 57-59.

[22] Robson, C.(2002). Real world research. Oxford Blackwell.

[23] Wertz, F. J. (2005). Phenomenological research methods for counseling psychology. Journal of Counseling Psychology, 52 167-177.

[24] Polkinghorne.(1983). Methodology for the Human Sciences. Albany Suny Press.

[25] Helsinki, D. O.(1964). World medical association declaration of Helsinki.

[26] Steimer. ( 2002) . The biology of fear- and anxiety-related behaviors. Dialogues in Clinical Neuroscience - Vol 4 . No.

[27] Mark, Stueve, Salzinger and Richard Feldman. (2010). Normalization of Violence among Inner-City Youth: A Formulation for Research American Journal of Orthopsychiatry Volume 72, Issue 1, pages 92-101. 